\title{
Functionalized Scaffold and Barrier Membrane with Anti-BMP-2 Monoclonal Antibodies for Alveolar Ridge Preservation in a Canine Model
}

\author{
Seiko Min (D), ${ }^{1}$ Taewan Kim, ${ }^{2}$ Oksu Kim, ${ }^{3}$ Carames Goncalo, ${ }^{4}$ Tadahiko Utsunomiya, ${ }^{5}$ \\ Takashi Matsumoto, ${ }^{6}$ Kayo Kuyama, ${ }^{5}$ and Nikola Angelov ${ }^{1}$ \\ ${ }^{1}$ Department of Periodontics and Dental Hygiene, University of Texas Health Science Center at Houston, Houston, TX, USA \\ ${ }^{2}$ Department of Periodontics, University of Pennsylvania School of Dental Medicine, Philadelphia, PA, USA \\ ${ }^{3}$ Department of Periodontology, Dental Research Institute, School of Dentistry, Chonnam National University, \\ Gwangju, Republic of Korea \\ ${ }^{4}$ Department of Periodontology, Implantology Institute, Lisbon, Portugal \\ ${ }^{5}$ Department of Pathology, School of Dentistry, Nihon University at Matsudo, Chiba, Japan \\ ${ }^{6}$ Division of Diagnostic Pathology, Nihon University Hospital School of Dentistry at Matsudo, Chiba, Japan
}

Correspondence should be addressed to Seiko Min; seiko.s.min@uth.tmc.edu

Received 6 June 2020; Accepted 4 August 2020; Published 23 September 2020

Guest Editor: Paolo Pesce

Copyright (c) 2020 Seiko Min et al. This is an open access article distributed under the Creative Commons Attribution License, which permits unrestricted use, distribution, and reproduction in any medium, provided the original work is properly cited.

Introduction. The aim of this study was to investigate the ability of anti-bone morphogenetic protein 2 monoclonal antibody (antiBMP-2 mAb) to functionalize scaffolds to mediate bone regeneration in a canine model. Materials and Methods. The mandibular right premolar 4 (PM4) was extracted in eight beagle dogs and grafted with anti-BMP-2 mAb+anorganic bovine bone mineral with $10 \%$ collagen (ABBM-C) and porcine bilayer native collagen membrane (CM). The ABBM-C and CM were functionalized with either anti-BMP-2 mAb (test group) or an isotype matched control mAb (control group). Animals were euthanized at 12 weeks for radiographic, histologic, and histomorphometric analyses. Outcomes were compared between groups. Results. 3D imaging using cone beam computed tomography (CBCT) revealed that sites treated with ABBM-C and CM functionalized with antiBMP-2 mAb exhibited significantly more remaining bone width near the alveolar crest, as well as buccal bone height, compared with control groups. Histologic and histomorphometric analyses demonstrated that in anti-BMP- 2 mAb-treated sites, total tissue volume was significantly higher in the coronal part of the alveolar bone crest compared with control sites. In anti-BMP-2 $\mathrm{mAb}$-treated sites, bone formation was observed under the barrier membrane. Conclusion. Functionalization of the ABBM-C scaffold and CM appeared to have led to bone formation within healing alveolar bone sockets.

\section{Introduction}

Numerous studies have demonstrated that significant bone resorption occurs as an inevitable biological event following tooth extraction without additional intervention [1-11]. The rates of loss of alveolar bone width and height in the first three months following extraction are approximately $0.25 \mathrm{~mm}$ and $0.2 \mathrm{~mm}$, respectively [7]. A systematic review concluded that in the first six months, the dimensional changes in the alveolar ridge after tooth extraction lead to a mean horizontal width loss of $3.8 \mathrm{~mm}$ and a mean vertical height loss of $1.24 \mathrm{~mm}$ [12]. Moreover, spontaneous postextraction healing leads to significant alveolar bone contour loss [13].

The magnitude of bone resorption appears more prominent when the initial thickness of the buccal bone wall is less than $1.0 \mathrm{~mm}$ [6]. The prevalence of a thin buccal wall was investigated and a study revealed that most teeth in the anterior maxilla have a thin buccal bone [14].

The subsequent dimensional loss of the alveolar ridge following tooth extraction often results in different complications, including insufficient bone volume for dental implant 


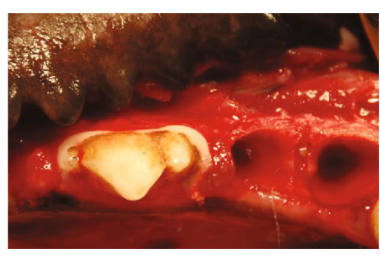

(a)

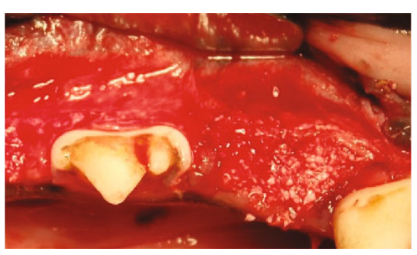

(b)

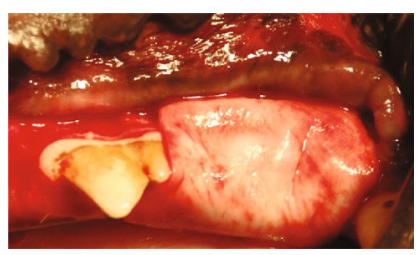

(c)

Figure 1: (a) The mandibular right premolar 4 (PM4) was extracted with flap elevation as atraumatically as possible. (b) The sockets were filled with anorganic bovine bone mineral with $10 \%$ collagen (ABBM-C) functionalized with either anti-bone morphogenetic protein 2 monoclonal antibody (anti-BMP-2 mAb, test group) or isotype matched control mAb (control group). (c) The sockets filled with ABBM$\mathrm{C}$ were covered by porcine bilayer native collagen membrane (CM) functionalized with either anti-BMP-2 mAb or isotype matched control $\mathrm{mAb}$. The marginal gingiva was then approximated to achieve primary wound closure with a nonresorbable suture.

placement in the optimal position and an esthetic defect. The esthetic complication such as a peri-implant soft tissue deficiency can be caused mostly by implant malposition [15].

To minimize the postextraction alveolar ridge dimensional loss, systematic reviews have recommended socket grafting at the time of extraction for ridge preservation [16, 17]. Various biomaterials used for ridge preservation have been evaluated including autograft $[18,19]$, allograft [20], xenograft [18, 21-25], and alloplast [24, 26-28]. These graft materials have been protected by different barrier devices, including resorbable membranes $[20,29,30]$, nonresorbable membranes [31], autogenous soft tissue plugs [32], and extraction socket devices [7-11].

Tissue engineering strategies that combine osteoconductive scaffolds with osteoinductive mediators, such as recombinant human bone morphogenetic protein 2 (rhBMP-2), have been reported [33-37]. Application of rhBMP-2 has been expanded for bone repair; however, the numbers of reported complications have been increasing [38-48].

As an alternative approach to using rhBMP-2, the application of anti-bone morphogenetic protein 2 monoclonal antibody (anti-BMP-2 mAb) was proposed to capture endogenous BMP-2 and homologous ligands in an approach known as antibody-mediated osseous regeneration (AMOR) [49]. Anti-BMP-2 mAbs are able to mediate differentiation of local progenitor stem cells into osteoblast-like cells, thereby promoting bone repair and regeneration. Anti-BMP-2 mAbs can capture endogenous BMPs that supply the signals for repairing different types of bony defects, such as BMP-2, BMP-4, and BMP-7. The capability of AMOR has been tested in various defect models [49-57].

This exploratory study used an AMOR approach in a canine model to investigate a potential therapeutic intervention for preserving the alveolar ridge following tooth extraction. The anti-BMP-2 mAb was employed to functionalize both a scaffold and a barrier membrane.

\section{Materials and Methods}

2.1. Animals. The research protocol of this study was approved by the Institutional Animal Care and Use Committee (IACUC) of the University of Southern California (USC, Los Angeles, CA, USA). Eight beagle dogs (four years old, weighing 10 to $11 \mathrm{~kg}$ ) were used in this study and maintained on a soft diet with food and water ad libitum.

\subsection{Materials}

2.2.1. Antibodies and Scaffold. The experimental $\mathrm{mAb}$ was a chimeric anti-BMP-2 mAb with cross-reactivity to BMP-4 and BMP-7. The control $\mathrm{mAb}$ was an isotype matched $\mathrm{mAb}$ specific for the KLH peptide that had no specific affinity for BMP-2 [54]. A concentration of $25 \mu \mathrm{g} / \mathrm{ml}$ of $\mathrm{mAb}$ was chosen based on the results of our previous studies [54]. Anti-BMP-2 mAb and isotype matched control mAb were immobilized on deproteinized anorganic bovine bone mineral with $10 \%$ collagen (ABBM-C; Bio-Oss Collagen ${ }^{\circledR}$, Geistlich, Pharma AG, Wolhusen, Switzerland) as well as porcine bilayer native collagen membrane (CM; Bio-Gide ${ }^{\circledR}$ membrane, Geistlich, Pharma AG, Wolhusen, Switzerland) as previously described [54]. Briefly, the ABBM-C and CM were incubated at room temperature with $\mathrm{mAb}$ diluted with phosphate-buffered saline (PBS) for one hour prior to implantation into the sockets after tooth extraction. All antibody preparations were made by two of the coauthors (S.M., O.K.).

2.2.2. Surgical Protocol. Preoperatively, animals were given atropine $(0.05 \mathrm{mg} / \mathrm{kg})$ and sedated with ketamine $(10 \mathrm{mg} / \mathrm{kg}$ subcutaneously). Ketamine/xylazine was administered to induce anesthesia. Animals were intubated and ventilated with an isoflurane/oxygen machine. Anesthesia was maintained by isoflurane (1-4\%). Animals were draped and then periorally swabbed with cetrimide ( $1 \%$ solution), followed by chlorohexidine gluconate ( $0.05 \%$ solution). Before surgeries, dental prophylaxis was performed and all surgical sites were swabbed with chlorhexidine gluconate ( $0.12 \%$ solution). After intravenous ketamine $(5 \mathrm{mg} / \mathrm{ml})$ and intramuscular tiletamine-zolazepam $(5-10 \mathrm{mg} / \mathrm{kg})$ were administered, local anesthesia was achieved by using lidocaine $\mathrm{HCl}(2 \%)$ with $1: 100,000$ epinephrine. The mandibular right premolar 4 (PM4) was then extracted with flap elevation as atraumatically as possible in each of the eight dogs (Figure 1(a)). Then, the sockets were filled with ABBM-C functionalized with either anti-BMP-2 mAb or isotype matched control $\mathrm{mAb}$ (Figure 1(b)). After the sockets were filled with ABBM-C, they were covered by functionalized $\mathrm{CM}$ with either antiBMP-2 mAb or isotype matched control mAb (Figure 1(c)). The marginal gingiva was then approximated to achieve primary wound closure with nonresorbable polytetrafluoroethylene (PTFE) monofilament suture (4-0 Cytoplast $^{\mathrm{TM}}$ 


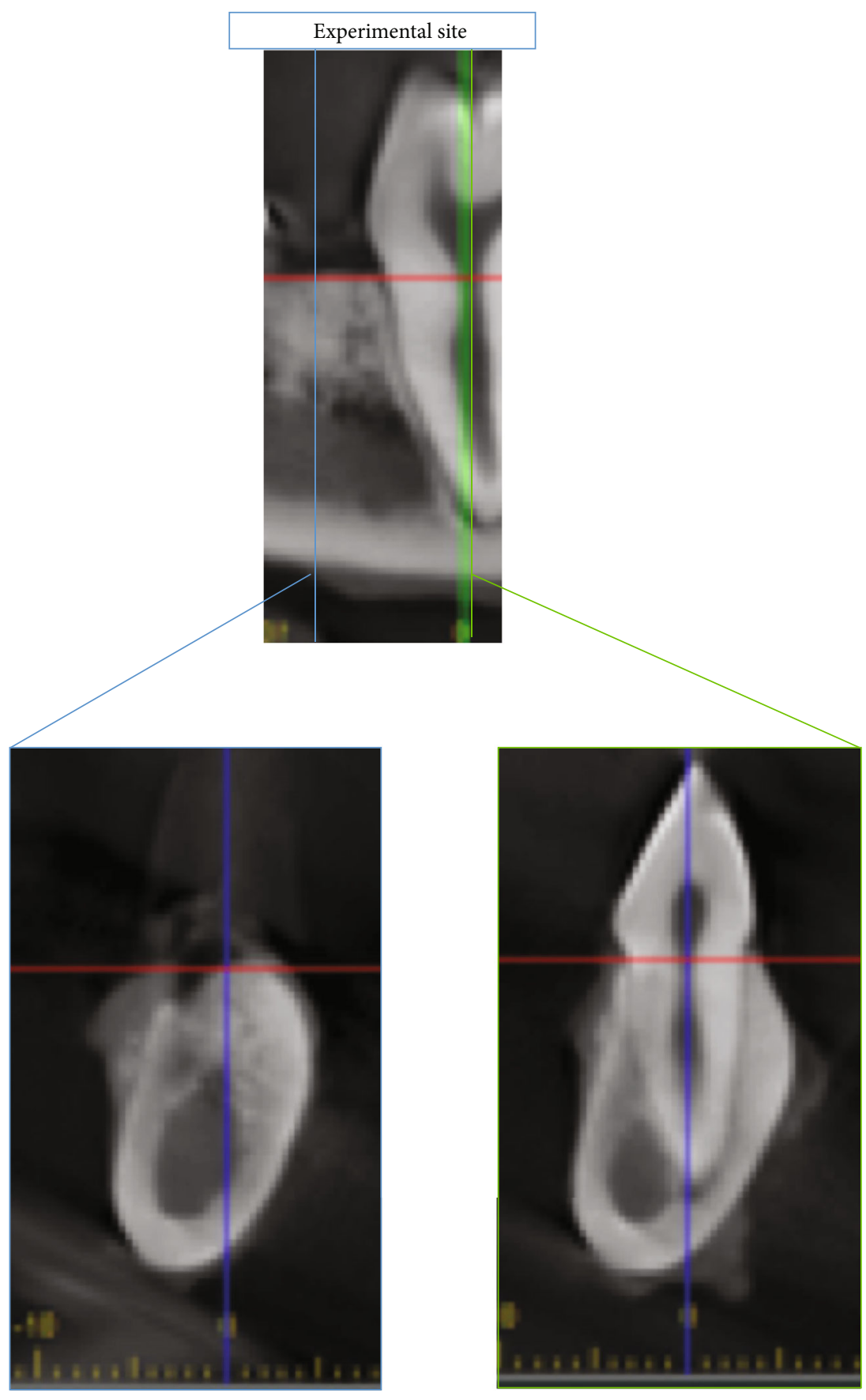

(a)

Figure 2: Continued. 

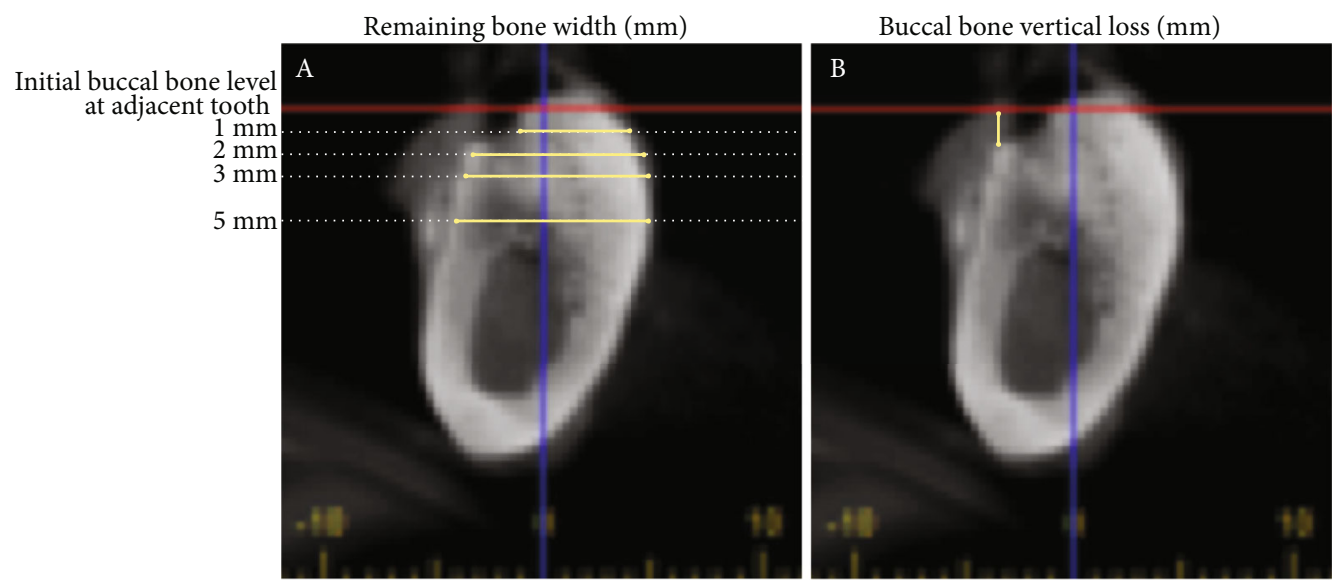

(b)

FIgURE 2: Repeatable anatomical structures such as the adjacent crest level (red line in upper image) and long axis of the adjacent tooth (blue line in lower two images) were used as references to measure dimensional alveolar bone change. (a) Remaining bone width at different levels of $1 \mathrm{~mm}, 2 \mathrm{~mm}, 3 \mathrm{~mm}$, and $5 \mathrm{~mm}$ from the bone crest at the adjacent tooth and (b) buccal bone height level relative to bone crest at the adjacent tooth were measured at the buccal thirds of the examined alveolus.

suture; Osteogenics, Lubbock, TX, USA). Three of the coauthors (S.M., O.K., and C.G.) performed all surgical procedures. The eight extraction socket sites were then randomly assigned to either of the two experimental treatment groups: (1) test $(N=4)$ : anti-BMP-2 mAb+ABBM-C+CM and (2) control $(N=4)$ : isotype matched control mAb+ABBM-C $+\mathrm{CM}$.

2.2.3. Postoperative Care. After surgery, the animals were maintained on a soft diet. On alternate days, oral hygiene was performed by applying chlorhexidine gluconate $(0.12 \%$ solution) with an ultrasoft toothbrush. Postoperative analgesia was administered 2 times per day for 2 days (buprenorphine, $0.05 \mathrm{mg} / \mathrm{kg}$ weight), after which the comfort level of the animals was assessed and additional analgesia was provided as needed. Sutures were removed 14 days later. At 12 weeks after tooth extraction, the animals were euthanized so that cone beam computed tomography (CBCT) and histologic and histomorphometric analyses could be conducted. The mandible of each dog was block resected, labeled, and fixed for 10 days in a $10 \%$ buffered formalin solution.

2.2.4. CBCT Analysis. Resected mandibles were imaged with CBCT (J. Morita Veraviewepocs ${ }^{\circledR}$ 3D F40, J Morita USA, Irvine, CA, USA), followed by quantitative analysis to measure mineralized tissue detected at defined locations within the grafted sites. Each of the specimens was placed in a sample holder and was scanned using high resolution. After scanning, the acquired data were imported into 3D image analysis software (i-Dixel 2.0 software, J Morita USA, Irvine, CA, USA) for quantitative analysis. A global thresholding procedure was used to segment the bone tissues. Bone tissues within the defects were defined using a threshold equal to $-360 \mathrm{HU}$. The proportion of bone volume occupying the defect virtual space was measured, allowing quantitative comparisons between the test and control groups. CBCT linear measurements were made at 12 weeks postsurgery, as follows: (1) remaining bone width at different levels $(1,2,3$, and
$5 \mathrm{~mm}$ relative to the bone crest of the adjacent first molar tooth (Figure 2(a)) and (2) buccal bone vertical level relative to the crestal bone of the adjacent first molar (Figure 2(b)). One coauthor (S.M.) performed all CBCT measurements. Repeated measurements were conducted on $10 \%$ of the sites selected randomly. The first and second measurements differed by less than $5 \%$, demonstrating intrarater reproducibility of the analysis.

2.2.5. Histologic and Histomorphometric Analyses. Harvested biopsy samples were fixed in $4 \%$ paraformaldehyde followed by decalcification in 10\% EDTA for 14 days. Excised specimens were embedded in paraffin and then serially sectioned ( $4 \mu \mathrm{m}$ thickness) and placed on glass slides. Deparaffinization was performed by immersing in xylene, followed by decreasing ethanol concentrations and washing with water. AzanMallory staining was applied to the sections. Images were qualitatively examined under a microscope (CX21 ${ }^{\circledR}$ Olympus Optical Co., Tokyo, Japan). Histomicrographs were captured with a digital camera and analyzed by using image analysis software (Soft Image System GmbH, Münster, Germany). NIH ImageJ software (U.S. National Institutes of Health, Bethesda, Maryland, USA) was used for histomorphometric analysis to measure the total tissue volume within different areas at $0-1 \mathrm{~mm}$ coronal to the lingual bone crest and at $0-1 \mathrm{~mm}, 1-2 \mathrm{~mm}$, and $2-3 \mathrm{~mm}$ apical to the lingual bone crest (Figure 3). One coauthor (T. K.) performed all histomorphometric measurements. Standard methods and nomenclature of the American Society for Bone and Mineral Research (ASBMR) were utilized to define various components of the specimens [58].

2.2.6. Statistical Analysis. The mean and standard deviations were calculated for CBCT and histomorphometric analysis. The Mann-Whitney $U$ test was used for pairwise comparisons of the remaining bone width and buccal bone height, and total tissue volume was calculated at different locations. The SPSS software program (IBM SPSS statistics 23, IBM, 


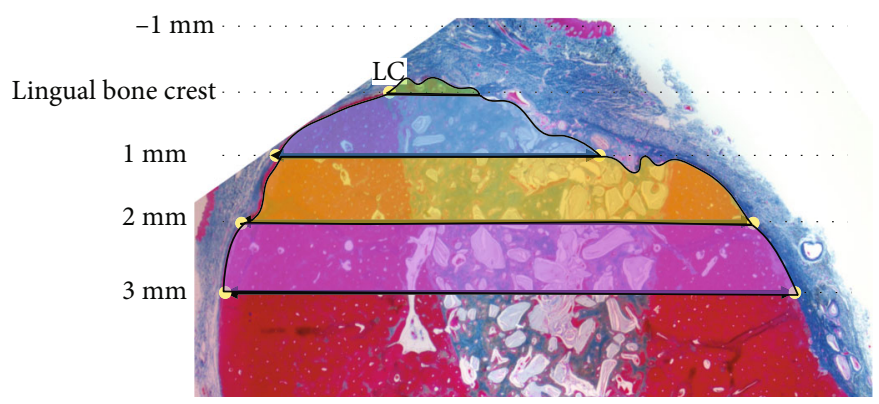

FIGURE 3: Landmarks for histomorphometric analysis, showing lingual crest (LC) as a relatively stable reference. Additional landmarks relative to the $\mathrm{LC}$ are represented at $1 \mathrm{~mm}$ coronal (i.e., $-1 \mathrm{~mm}$ ) and 1, 2, and $3 \mathrm{~mm}$ apical to the LC. The amounts of total tissue volume in different zones relative to the LC (0-1 mm coronal, $0-1 \mathrm{~mm}$ apical, 1-2 $\mathrm{mm}$ apical, and 2-3 mm apical) were measured.
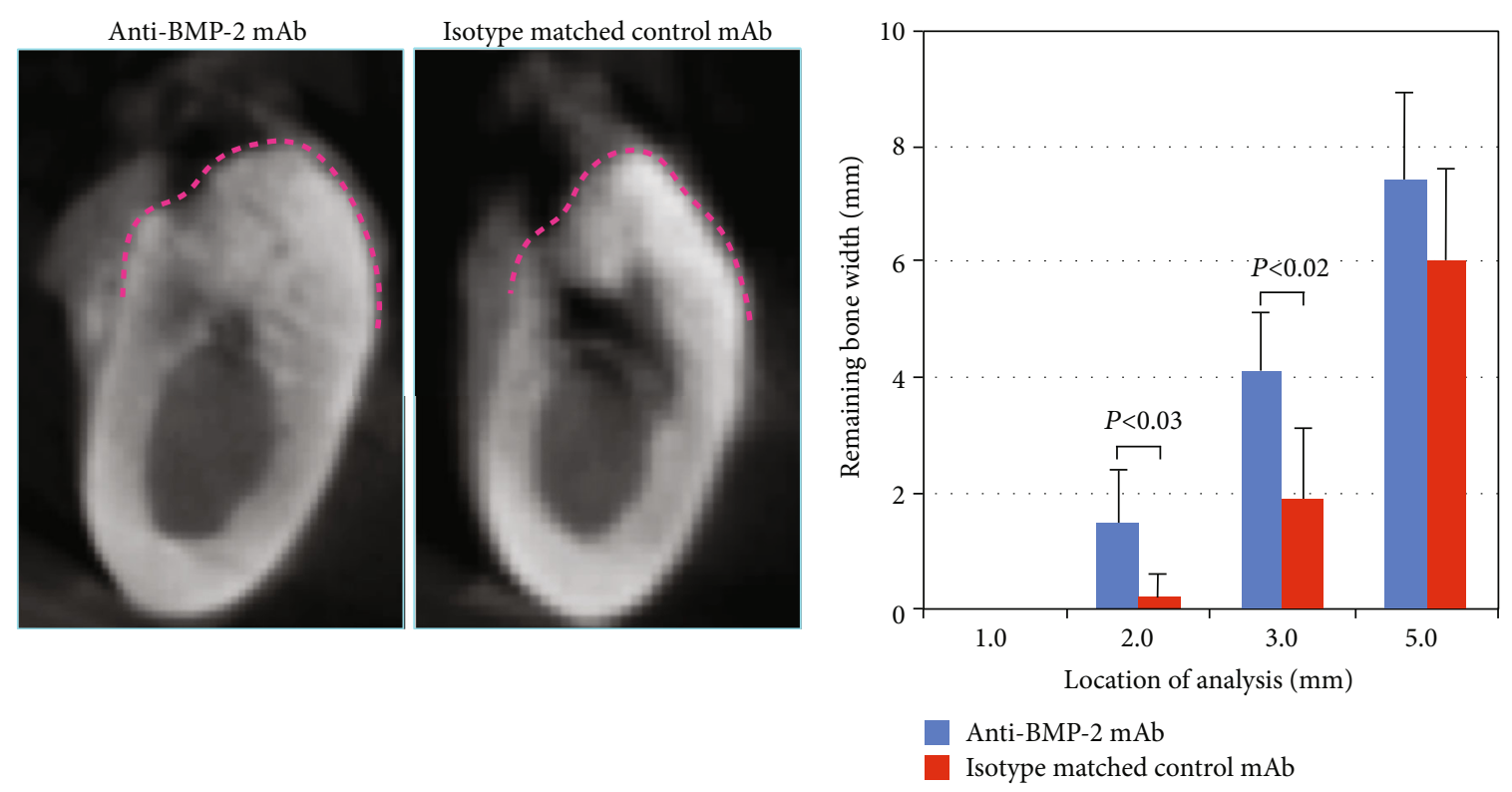

(a)

(b)

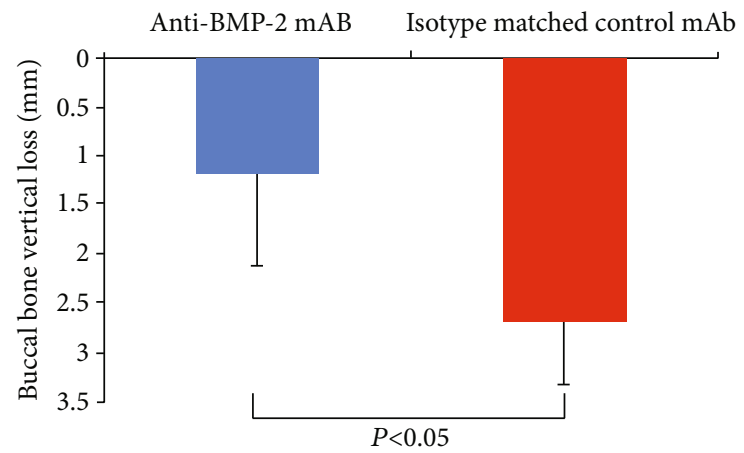

(c)

FIGURE 4: (a) Representative cone bean computed tomography (CBCT) images of anti-bone morphogenetic protein 2 monoclonal antibody(anti-BMP-2 mAb-) treated site and isotype matched control mAb-treated site. (b) Remaining bone width at 1,2,3, and $5 \mathrm{~mm}$ from the bone crest at the adjacent tooth: a statistically significant difference in remaining bone width at $2 \mathrm{~mm}$ and $3 \mathrm{~mm}$ was found between the test group $(N=4)$ and control group $(N=4)(P=0.03, P=0.02$, respectively). (c) Bone height level at buccal aspect (mm): the amounts of buccal bone height loss in the anti-BMP-2 mAb-treated sites $(N=4)$ and the isotype matched control mAb-treated sites $(N=4)$ were $1.17 \pm 0.94 \mathrm{~mm}$ and $2.69 \pm 0.63 \mathrm{~mm}$, respectively, and were statistically significantly different $(P=0.03)$. 
TABLE 1: Remaining bone width at $1,2,3$, and $5 \mathrm{~mm}$ relative to the adjacent crestal bone.

\begin{tabular}{|c|c|c|c|c|}
\hline \multirow{2}{*}{ Treatment group } & \multicolumn{4}{|c|}{ Remaining bone width $(\mathrm{mm}$, mean $\pm \mathrm{SD})$ at four test sites } \\
\hline & $1 \mathrm{~mm}$ & $2 \mathrm{~mm}$ & $3 \mathrm{~mm}$ & $5 \mathrm{~mm}$ \\
\hline Anti-BMP-2 mAb & $0.0 \pm 0.0$ & $1.5 \pm 0.9^{*}$ & $4.1 \pm 1.0^{\dagger}$ & $7.4 \pm 1.5$ \\
\hline Isotype matched control $\mathrm{mAb}$ & $0.0 \pm 0.0$ & $0.2 \pm 0.4$ & $1.9 \pm 1.2$ & $6.0 \pm 1.6$ \\
\hline
\end{tabular}

For anti-BMP-2-treated sites vs. control sites: ${ }^{*} P=0.03$ and ${ }^{\dagger} P=0.02$. Anti-BMP-2 mAb: anti-bone morphogenetic protein 2 monoclonal antibody; SD: standard deviation.

Armonk, NY, USA) was used for statistical analysis and $P<0.05$ was considered to be statistically significant.

\section{Results}

3.1. Clinical Observations. All surgical sites healed uneventfully with minimal inflammation and no signs of infection.

3.2. CBCT Analysis. Representative CBCT images illustrate wider alveolar crest in experimental sites treated with scaffold and membrane functionalized with anti-BMP-2, compared with control sites (Figure 4(a)). The alveolar crest also appears to have higher density in the experimental site.

3.3. Quantitative Analysis of Bone Width. For anti-BMP-2 $\mathrm{mAb}$, the remaining mean bone widths in test sites at 1,2 , 3 , and $5 \mathrm{~mm}$ relative to the adjacent crestal bone were $0.0 \pm$ $0.0 \mathrm{~mm}, \quad 1.5 \pm 0.9 \mathrm{~mm}, 4.1 \pm 1.0 \mathrm{~mm}$, and $7.4 \pm 1.5 \mathrm{~mm}$, respectively (Figure 4(b), Table 1). Comparatively, the residual mean bone widths of control sites were $0.0 \pm 0.0 \mathrm{~mm}$, $0.2 \pm 0.4 \mathrm{~mm}, 1.9 \pm 1.2 \mathrm{~mm}$, and $6.0 \pm 1.6 \mathrm{~mm}$, respectively. The remaining bone widths at anti-BMP-2-treated sites were statistically significantly higher at 2 and $3 \mathrm{~mm}$ compared with control sites ( $P=0.03, P=0.02$, respectively).

3.4. Quantitative Analysis of Buccal Bone Height. For antiBMP-2 mAb, the buccal crest of anti-BMP-2-treated sites was located $1.17 \pm 0.94 \mathrm{~mm}$ apical to the crestal bone of adjacent teeth. In contrast, the buccal crest of control sites treated with isotype matched control $\mathrm{mAb}$ was located $2.69 \pm 0.63$ $\mathrm{mm}$ apical to that of adjacent teeth (Figure 4(c), Table 2). A statistically significant difference was found between antiBMP-2-treated sites and control sites $(P=0.03)$.

3.5. Histologic Observation. Histologic examination revealed well-defined extraction socket defects with clear demarcation between the woven bone and more mature lamellar bone by Azan-Mallory staining of both anti-BMP-2 mAb-treated sites and control sites (Figures 5(a) and 5(b)). The barrier $\mathrm{CM}$ persisted underneath mucosal tissues overlying the extraction orifice of test sites treated with anti-BMP-2 mAb (green dotted lines). In contrast, the CM in control sites appeared to have been significantly more resorbed, accompanied by in-growth of mucosal tissues into the graft. The superficial ABBM particles in control sites appeared to be mostly encapsulated in fibrous tissue (Figures 5(b) and $5(\mathrm{~d})$ ). The area underneath the CM in anti-BMP-2 mAbtreated sites was characterized by an abundance of osteoid bone surrounding residual graft particles, as well as vascular tissue (Figures 5(a) and 5(c)). The new bone found within
TABLE 2: Location of buccal crest relative to crestal bone of the adjacent teeth.

\begin{tabular}{lc}
\hline Treatment group & $\begin{array}{c}\text { Buccal bone height } \\
(\mathrm{mm}, \text { mean } \pm \mathrm{SD})\end{array}$ \\
\hline Anti-BMP-2 mAb & $1.17 \pm 0.94^{*}$ \\
Isotype matched control mAb & $2.69 \pm 0.63$ \\
\hline${ }^{*} P=0.03$ for anti-BMP-2-treated sites vs. control sites. Anti-BMP-2 $\mathrm{mAb}:$
\end{tabular}
anti-bone morphogenetic protein 2 monoclonal antibody.

test sites appeared to be characterized by reversal lines, marking the remodeling stage of osteogenesis. In contrast, the bone within control sites was more sparse and consisted of less mature woven bone (Figures 5(b) and 5(d)).

Osteogenesis was observed within the entire extraction socket of both the test and control sites (Figures 5(a) and 5(b)). A polarized pattern of osteogenesis was observed with the most mature bone in the apical region, gradually transitioning to less mature woven bone near the alveolar crest (Figures 5(a) and 5(b)).

3.6. Quantitative Histomorphometric Analysis. The landmarks used for quantitative histomorphometric analysis are shown in Figure 3. The results shown in Figure 6 and Table 3 demonstrated that sites treated with scaffold and CM functionalized with anti-BMP-2 (test), but not sites treated with isotype matched control $\mathrm{mAb}$, had bone growth coronal to the alveolar lingual crest $(P=0.01)$. In the zone up to $1 \mathrm{~mm}$ apical to the bone crest, there was significantly more bone volume in anti-BMP-2 mAb-treated sites than in control sites $(P=0.02)$.

\section{Discussion}

A variety of graft materials including autogenous [18, 19], xenogenic [18, 21-25], allogenic [20], and alloplastic [24, 26-28] materials have been used for grafting of extraction sockets for ridge preservation. In addition to these traditional grafts, newer scaffolds and biologics developed for tissue engineering have been adopted for ridge preservation [59-62]. These biologics have included growth factors and platelet concentrates [63-65].

One of the most investigated biologics is rhBMP-2, which was approved by the U.S. Food and Drug Administration (FDA) for clinical use to repair bone defects [66-68]. The growing clinical use of rhBMP-2 has been associated with numerous complications such as graft migration [69], formation of neutralizing antibodies against BMP-2 [69], and extreme edema that may obstruct the airway or affect critical 


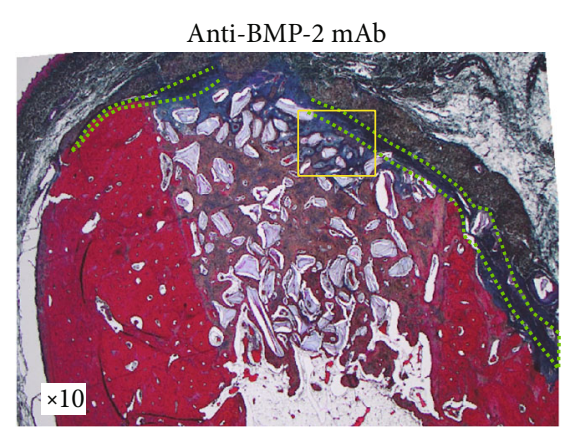

(a)

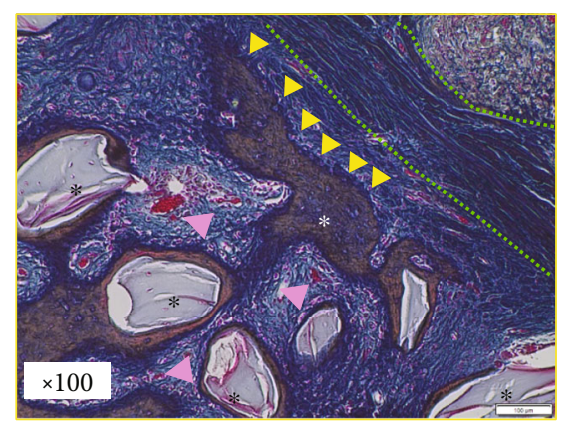

(c)

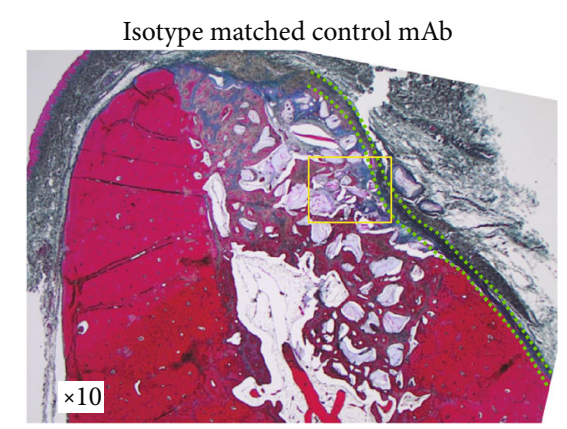

(b)

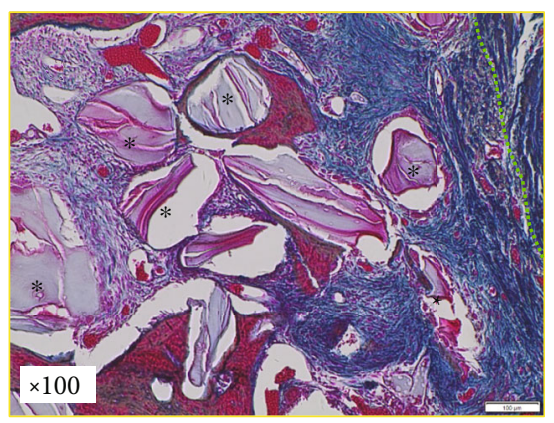

(d)

FIGURE 5: Histology at low magnification in the (a) anti-bone morphogenetic protein 2 monoclonal antibody- (anti-BMP-2 mAb-) treated site and (b) isotype matched control mAb site. Outline of alveolar bone in control sites appeared as a knife-edged shape due to buccal bone loss. The residual barrier collagen membrane (CM) was observed in both test and control sites (green dotted lines). Osteogenesis was observed within the entire extraction socket of both test and control sites. Histology at high magnification in (c) anti-BMP-2 mAb-treated and (d) isotype matched control mAb sites. The micrographs showed osteoblast-like cells (yellow arrowheads) as well as blood vessels (pink arrowheads) participating in active bone formation. The superficial anorganic bovine bone mineral (ABBM) particles (black asterisks in d) in control sites showed fibrotic encapsulation, while osteogenic cells as well as osteoid bone formation around residual ABBM graft particles were noted in test sites (white asterisk in c).

structures [46]. Additional disadvantages of exogenous growth factors (e.g., rhBMP-2) include a short biological half-life and lower biologic activity compared to the autogenous analog [70] that necessitates the use of high doses of rhBMP-2 to achieve the therapeutic effect.

To circumvent some of the problems associated with exogenous growth factors, a novel tissue engineering approach for bone regeneration known as AMOR was developed [49]. We previously reported that anti-BMP2-mAb induced osteogenic differentiation in vitro and de novo bone formation in vivo, by using different types of bone defects in animal models that have shown the ability of anti-BMP2$\mathrm{mAb}$ to mediate bone regeneration including rat $[49,50$, $52]$, rabbit [51], canine, and nonhuman primate [56, 57].

The current study is the first to investigate the efficacy of a scaffold and barrier membrane functionalized with antiBMP-2 mAb for ridge preservation in a canine model.

Following tooth extraction, the anti-BMP-2 $\mathrm{mAb}$ immobilized on the ABBM-C was implanted into an extraction socket and was protected by anti-BMP-2 mAb immobilized on a CM.

The present study showed that the anti-BMP- $2 \mathrm{mAb}-$ treated sites had statistically significantly greater remaining bone width and buccal bone height, as well as higher total tissue volume, compared with control $\mathrm{mAb}$-treated sites. These favorable outcomes may be attributed to the ability of the
anti-BMP-2 mAb to capture endogenous BMP-2, BMP-4, and BMP-7 and increase their in vivo persistence [50]. The barrier CM functionalized with anti-BMP-2 mAb was utilized not only for cell occlusion properties and spacemaking abilities but also for bioactive properties that promote bone regeneration by capturing endogenous BMP-2, BMP-4, and BMP-7.

Radiographic assessment demonstrated that both the buccal bone height level relative to the bone crest at an adjacent tooth and the remaining bone width at 2 and $3 \mathrm{~mm}$ relative to the bone crest at an adjacent tooth in the anti-BMP-2 $\mathrm{mAb}$-treated site was statistically significantly higher than that of the control mAb-treated site $(P=0.03)$. Furthermore, histologic observations in the anti-BMP-2 mAb-treated site revealed the presence of bone formation with deposition of active osteogenic cells, including osteoblast-like cells as well as osteoclast-like cells beneath the remaining barrier CM.

One of major findings from this study was that histomorphometric analysis showed a statistically significantly higher total tissue volume at $0-1 \mathrm{~mm}$ coronal as well as at $0-1 \mathrm{~mm}$ apical to the lingual bone crest in the anti-BMP-2 mAbtreated site compared to that in the control $\mathrm{mAb}$-treated site $(P<0.05)$. The alveolar crest contour in the anti-BMP-2 $\mathrm{mAb}$-treated sites was restored more significantly compared with that in the control $\mathrm{mAb}$-treated sites. Therefore, the current data demonstrated that the use of a scaffold and barrier 


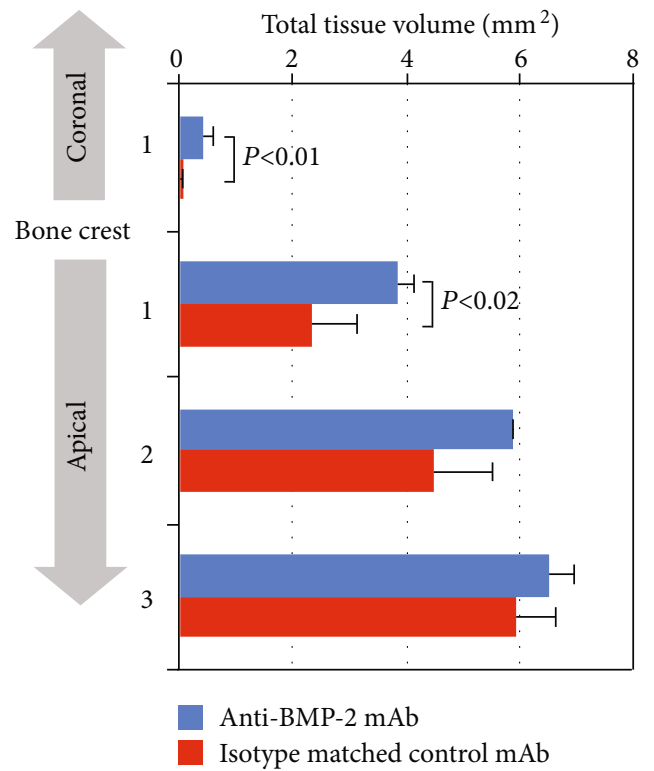

FIgURE 6: The amounts of total tissue volume within the extraction socket at $0-1 \mathrm{~mm}$ coronal to the lingual crest and at 0-1 mm, 1-2 mm, and $2-3 \mathrm{~mm}$ apical to the lingual crest. The anti-bone morphogenetic protein 2 monoclonal antibody- (anti-BMP-2 mAb-) treated sites $(N=4)$ revealed a statistically significant higher amount of total tissue volume at $0-1 \mathrm{~mm}$ coronal as well as at $0-1 \mathrm{~mm}$ apical of the alveolar bone crest relative to the lingual crest compared with the isotype matched control mAb-treated sites $(N=4)(P=0.01, P=0.02$, respectively). Landmarks used for the analysis are shown in Figure 3.

TABLE 3: Quantitative histomorphometric analysis of sites treated with scaffold and collagen membrane (CM) functionalized with anti-BMP$2 \mathrm{mAb}$.

\begin{tabular}{lcccc}
\hline \multirow{2}{*}{ Treatment group } & \multicolumn{3}{c}{ Total tissue volume (pixels, mean \pm SD) } \\
& $0-1 \mathrm{~mm}$ coronal & $0-1 \mathrm{~mm}$ apical & $1-2 \mathrm{~mm}$ apical & $5.87 \pm 0.03$ \\
\hline Anti-BMP-2 mAb & $0.45 \pm 0.16^{*}$ & $3.85 \pm 0.30^{\dagger}$ & $6.54 \pm 0.42$ \\
Isotype matched control mAb & $0.02 \pm 0.05$ & $2.32 \pm 0.82$ & $4.48 \pm 1.04$ & $5.93 \pm 0.72$ \\
\hline
\end{tabular}

For anti-BMP-2-treated sites vs. control sites: ${ }^{*} P=0.01$ and ${ }^{\dagger} P=0.02$. Landmarks used for the analysis are shown in Figure 3. Anti-BMP-2 mAb: anti-bone morphogenetic protein 2 monoclonal antibody; SD: standard deviation.

membrane functionalized with anti-BMP-2 mAb enhanced bone regeneration for ridge preservation. It is also worthwhile to note that in the present study, AMOR showed no signs of a severe inflammation reaction. This finding can possibly be attributed to the low concentration of anti-BMP-2 $\mathrm{mAb}$ that is needed to capture endogenous BMP-2 to enhance bone regeneration within the extraction socket.

The present study has a number of limitations, including a small sample size and lack of multiple time points to examine the kinetics of wound healing. We have plans to initiate additional studies with a larger sample size and longer duration to investigate the utility of AMOR for management of complex tooth extractions.

\section{Conclusion}

This study investigated the functionalization of a scaffold and barrier membrane with anti-BMP-2 mAb for extraction socket grafting in a canine model. The application of AMOR for socket grafting was accompanied by increased bone volume and more mature bone formation within the extraction sockets.

\section{Data Availability}

The data used to support the findings of this study are available from the corresponding author upon request.

\section{Disclosure}

This study was presented as a poster on April 4, 2018, at the University of Southern California Research Day by Dr. Taewan Kim.

\section{Conflicts of Interest}

The authors declare no conflicts of interest.

\section{Acknowledgments}

The authors would like to acknowledge Dr. Homayoun Zadeh for his assistance with the experiments described in this manuscript. This study was supported by a grant to Seiko Min from the Osteology Foundation (\#13-019). 


\section{References}

[1] K. Johnson, "A study of the dimensional changes occurring in the maxilla following tooth extraction," Australian Dental Journal, vol. 14, no. 4, pp. 241-244, 1969.

[2] J. Pietrokovski and M. Massler, "Alveolar ridge resorption following tooth extraction," The Journal of Prosthetic Dentistry, vol. 17, no. 1, pp. 21-27, 1967.

[3] L. Schropp, A. Wenzel, L. Kostopoulos, and T. Karring, "Bone healing and soft tissue contour changes following single-tooth extraction: a clinical and radiographic 12-month prospective study," The International Journal of Periodontics \& Restorative Dentistry, vol. 23, no. 4, pp. 313-323, 2003.

[4] M. G. Araújo and J. Lindhe, "Dimensional ridge alterations following tooth extraction. An experimental study in the dog," Journal of Clinical Periodontology, vol. 32, no. 2, pp. 212-218, 2005.

[5] J. M. Ten Heggeler, D. E. Slot, and G. A. Van der Weijden, "Effect of socket preservation therapies following tooth extraction in non-molar regions in humans: a systematic review," Clinical Oral Implants Research, vol. 22, no. 8, pp. 779-788, 2011.

[6] V. Chappuis, O. Engel, K. Shahim, M. Reyes, C. Katsaros, and D. Buser, "Soft tissue alterations in esthetic postextraction sites: a 3-dimensional analysis," Journal of Dental Research, vol. 94, Supplement 9, pp. 187S-193S, 2015.

[7] K. H. Ryu, S. Min, H. K. You et al., “Alveolar ridge dimensional changes following ridge preservation procedure using Socket$\left.\mathrm{KAP}^{\mathrm{TM}}\right)$ : exploratory study of serial cone-beam computed tomography and histologic analysis in canine model," Clinical Oral Implants Research, vol. 27, no. 9, pp. 1144-1151, 2016.

[8] S. Min, Y. Liu, J. Tang et al., "Alveolar ridge dimensional changes following ridge preservation procedure with novel devices: part 1-CBCT linear analysis in non-human primate model," Clinical Oral Implants Research, vol. 27, no. 1, pp. 97-105, 2016.

[9] M. Omran, S. Min, A. Abdelhamid, Y. Liu, and H. H. Zadeh, "Alveolar ridge dimensional changes following ridge preservation procedure: part-2 - CBCT 3D analysis in non-human primate model," Clinical Oral Implants Research, vol. 27, no. 7, pp. 859-866, 2016.

[10] A. Abdelhamid, M. Omran, and N. Bakhshalian, “An open randomized controlled clinical trial to evaluate ridge preservation and repair using SocketKAP ${ }^{\mathrm{TM}}$ and SocketKAGE ${ }^{\mathrm{TM}}$ : part 2 three-dimensional alveolar bone volumetric analysis of CBCT imaging," Clinical Oral Implants Research, vol. 27, no. 6, pp. 631-639, 2016.

[11] Y. Su, J. Tang, S. Min et al., "Alveolar ridge dimensional changes following ridge preservation procedure with novel devices: part 3 - histological analysis in non-human primate model," Clinical Oral Implants Research, vol. 28, no. 11, pp. e252-e261, 2017.

[12] W. L. Tan, T. L. T. Wong, M. C. M. Wong, and N. P. Lang, “A systematic review of post-extractional alveolar hard and soft tissue dimensional changes in humans," Clinical Oral Implants Research, vol. 23, pp. 1-21, 2012.

[13] H. H. Zadeh, A. Abdelhamid, M. Omran, N. Bakhshalian, and D. Tarnow, "An open randomized controlled clinical trial to evaluate ridge preservation and repair using SocketKAP тм and SocketKAGE ${ }^{\mathrm{Tm}}$ : part 1-three-dimensional volumetric soft tissue analysis of study casts," Clinical Oral Implants Research, vol. 27, no. 6, pp. 640-649, 2016.
[14] A. L. Januário, W. R. Duarte, M. Barriviera, J. C. Mesti, M. G. Araújo, and J. Lindhe, "Dimension of the facial bone wall in the anterior maxilla: a cone-beam computed tomography study," Clinical Oral Implants Research, vol. 22, no. 10, pp. 1168-1171, 2011.

[15] A. Monje, P. Galindo-Moreno, T. F. Tözüm, F. Suárez-López del Amo, and H. L. Wang, "Into the paradigm of local factors as contributors for peri-implant disease: short communication," The International Journal of Oral \& Maxillofacial Implants, vol. 31, no. 2, pp. 288-292, 2016.

[16] C. H. Hämmerle, M. G. Araújo, and M. Simion, "On behalf of the osteology consensus group 2011. Evidence-based knowledge on the biology and treatment of extraction sockets," Clinical Oral Implants Research, vol. 23, pp. 80-82, 2011.

[17] F. Vignoletti, P. Matesanz, D. Rodrigo, E. Figuero, C. Martin, and M. Sanz, "Surgical protocols for ridge preservation after tooth extraction. A systematic review," Clinical Oral Implants Research, vol. 23, pp. 22-38, 2011.

[18] M. G. Araújo and J. Lindhe, "Socket grafting with the use of autologous bone: an experimental study in the dog," Clinical Oral Implants Research, vol. 22, no. 1, pp. 9-13, 2011.

[19] W. Becker, B. E. Becker, and R. Caffesse, "A comparison of demineralized freeze-dried bone and autologous bone to induce bone formation in human extraction sockets," Journal of Periodontology, vol. 65, no. 12, pp. 1128-1133, 1994.

[20] J. M. Iasella, H. Greenwell, R. L. Miller et al., "Ridge preservation with freeze-dried bone allograft and a collagen membrane compared to extraction alone for implant site development: a clinical and histologic study in humans," Journal of Periodontology, vol. 74, no. 7, pp. 990-999, 2003.

[21] D. Carmagnola, P. Adriaens, and T. Berglundh, "Healing of human extraction sockets filled with Bio-Oss," Clinical Oral Implants Research, vol. 14, no. 2, pp. 137-143, 2003.

[22] D. Cardaropoli, L. Tamagnone, A. Roffredo, L. Gaveglio, and G. Cardaropoli, "Socket preservation using bovine bone mineral and collagen membrane: a randomized controlled clinical trial with histologic analysis," The International Journal of Periodontics \& Restorative Dentistry, vol. 32, no. 4, pp. 421430, 2012.

[23] D. Cardaropoli, L. Tamagnone, A. Roffredo, and L. Gaveglio, "Relationship between the buccal bone plate thickness and the healing of postextraction sockets with/without ridge preservation," The International Journal of Periodontics \& Restorative Dentistry, vol. 34, no. 2, pp. 211-217, 2014.

[24] G. A. Kotsakis, M. Salama, V. Chrepa, J. E. Hinrichs, and P. Gaillard, "A randomized, blinded, controlled clinical study of particulate anorganic bovine bone mineral and calcium phosphosilicate putty bone substitutes for socket preservation," The International Journal of Oral \& Maxillofacial Implants, vol. 29, no. 1, pp. 141-151, 2014.

[25] A. Barone, P. Toti, A. Quaranta et al., "Clinical and histological changes after ridge preservation with two xenografts: preliminary results from a multicentre randomized controlled clinical trial," Journal of Clinical Periodontology, vol. 44, no. 2, pp. 204-214, 2017.

[26] M. R. Norton and J. Wilson, "Dental implants placed in extraction sites implanted with bioactive glass: human histology and clinical outcome," The International Journal of Oral \& Maxillofacial Implants, vol. 17, no. 2, pp. 249-257, 2002.

[27] P. M. Camargo, V. Lekovic, M. Weinlaender et al., "Influence of bioactive glass on changes in alveolar process dimensions after exodontia," Oral Surgery, Oral Medicine, Oral Pathology, 
Oral Radiology, and Endodontics, vol. 90, no. 5, pp. 581-586, 2000.

[28] R. E. Jung, A. Philipp, B. M. Annen et al., "Radiographic evaluation of different techniques for ridge preservation after tooth extraction: a randomized controlled clinical trial," Journal of Clinical Periodontology, vol. 40, no. 1, pp. 90-98, 2013.

[29] G. Favero, N. P. Lang, E. De Santis, B. G. Gonzalez, M. T. Schweikert, and D. Botticelli, "Ridge preservation at implants installed immediately after molar extraction. An experimental study in the dog," Clinical Oral Implants Research, vol. 24, no. 3, pp. 255-261, 2013.

[30] E. T. Scheyer, P. Schupbach, and M. K. McGuire, "A histologic and clinical evaluation of ridge preservation following grafting with demineralized bone matrix, cancellous bone chips, and resorbable extracellular matrix membrane," The International Journal of Periodontics \& Restorative Dentistry, vol. 32, no. 5, pp. 543-552, 2012.

[31] B. K. Bartee, "Evaluation of a new polytetrafluoroethylene guided tissue regeneration membrane in healing extraction sites," The Compendium of Continuing Education in Dentistry, vol. 19, pp. 1256-1258, 1998.

[32] R. E. Jung, D. W. Siegenthaler, and C. H. Hämmerle, "Postextraction tissue management: a soft tissue punch technique," The International Journal of Periodontics \& Restorative Dentistry, vol. 24, no. 6, pp. 545-553, 2004.

[33] L. Krishnan, L. B. Priddy, C. Esancy et al., "Hydrogel-based delivery of rhBMP-2 improves healing of large bone defects compared with autograft," Clinical Orthopaedics and Related Research, vol. 473, no. 9, pp. 2885-2897, 2015.

[34] G. Guven, B. A. Gultekin, G. S. Guven, E. Guzel, S. Furat, and S. Ersanli, "Histologic and histomorphometric comparison of bone regeneration between bone morphogenetic protein-2 and platelet-derived growth factor-BB in experimental groups," The Journal of Craniofacial Surgery, vol. 27, no. 3, pp. 805-809, 2016.

[35] W. Li, S. Zhu, and J. Hu, "Bone regeneration is promoted by orally administered bovine lactoferrin in a rabbit tibial distraction osteogenesis model," Clinical Orthopaedics and Related Research, vol. 473, no. 7, pp. 2383-2393, 2015.

[36] E. G. Machado, J. P. M. Issa, F. A. T. de Figueiredo et al., "A new heterologous fibrin sealant as scaffold to recombinant human bone morphogenetic protein-2 (rhBMP-2) and natural latex proteins for the repair of tibial bone defects," Acta Histochemica, vol. 117, no. 3, pp. 288-296, 2015.

[37] S. Subramanian, A. Mitchell, W. Yu, S. Snyder, K. Uhrich, and J. P. O'Connor, "Salicylic acid-based polymers for guided bone regeneration using bone morphogenetic protein-2," Tissue Engineering. Part A, vol. 21, no. 13-14, pp. 2013-2024, 2015.

[38] B. Skovrlj, S. M. Koehler, P. A. Anderson et al., "Association between BMP-2 and carcinogenicity," Spine, vol. 40, no. 23, pp. 1862-1871, 2015.

[39] J. W. Savage, M. P. Kelly, S. A. Ellison, and P. A. Anderson, “A population-based review of bone morphogenetic protein: associated complication and reoperation rates after lumbar spinal fusion," Neurosurgical Focus, vol. 39, no. 4, article E13, 2015.

[40] C. P. Hofstetter, A. S. Hofer, and A. D. Levi, "Exploratory meta-analysis on dose-related efficacy and morbidity of bone morphogenetic protein in spinal arthrodesis surgery," Journal of Neurosurgery. Spine, vol. 24, no. 3, pp. 457-475, 2016.

[41] P. S. Brannan, R. G. Gaston, B. J. Loeffler, and D. R. Lewis, "Complications with the use of BMP-2 in scaphoid nonunion surgery," The Journal of Hand Surgery, vol. 41, no. 5, pp. $602-$ 608, 2016.

[42] M. Bannwarth, J. C. Kleiber, B. Marlier, C. Eap, J. Duntze, and C. F. Litre, "Ectopic bone formation with joint impingement after posterior lumbar fusion with rhBMP-2," Orthopaedics \& Traumatology, Surgery \& Research, vol. 102, no. 2, pp. 255-256, 2016.

[43] L. Shi, W. Sun, F. Gao, L. Cheng, and Z. Li, "Heterotopic ossification related to the use of recombinant human BMP-2 in osteonecrosis of femoral head," Medicine (Baltimore), vol. 96, no. 27, article e7413, 2017.

[44] J. Z. Guzman, R. K. Merrill, J. S. Kim et al., "Bone morphogenetic protein use in spine surgery in the United States: how have we responded to the warnings?," The Spine Journal, vol. 17, no. 9, pp. 1247-1254, 2017.

[45] F. Y. Liu, D. L. Yang, W. Z. Huang et al., "Risk factors for dysphagia after anterior cervical spine surgery: a meta-analysis," Medicine (Baltimore), vol. 96, no. 10, article e6267, 2017.

[46] N. Stiel, T. N. Hissnauer, M. Rupprecht et al., "Evaluation of complications associated with off-label use of recombinant human bone morphogenetic protein-2 (rhBMP-2) in pediatric orthopaedics," Journal of Materials Science. Materials in Medicine, vol. 27, no. 12, p. 184, 2016.

[47] A. T. Villavicencio and S. Burneikiene, "RhBMP-2-induced radiculitis in patients undergoing transforaminal lumbar interbody fusion: relationship to dose," The Spine Journal, vol. 16, no. 10, pp. 1208-1213, 2016.

[48] A. L. Laurie, Y. Chen, R. Chou, and R. Fu, "Meta-analysis of the impact of patient characteristics on estimates of effectiveness and harms of recombinant human bone morphogenetic Protein-2 in lumbar spinal fusion," Spine (Phila $\mathrm{Pa}$ 1976), vol. 41, no. 18, pp. E1115-E1123, 2016.

[49] M. O. Freire, H. K. You, J. K. Kook, J. H. Choi, and H. H. Zadeh, "Antibody-mediated osseous regeneration: a novel strategy for bioengineering bone by immobilized anti-bone morphogenetic protein-2 antibodies," Tissue Engineering. Part A, vol. 17, no. 23-24, pp. 2911-2918, 2011.

[50] M. O. Freire, H. K. Kim, J. K. Kook, A. Nguyen, and H. H. Zadeh, "Antibody-mediated osseous regeneration: the early events in the healing response," Tissue Engineering. Part A, vol. 19, no. 9-10, pp. 1165-1174, 2013.

[51] M. Freire, J.-H. Choi, A. Nguyen et al., "Application of AMOR in craniofacial rabbit bone bioengineering," BioMed Research International, vol. 2015, Article ID 628769, 7 pages, 2015.

[52] A. Moshaverinia, S. Ansari, C. Chen et al., "Co-encapsulation of anti-BMP2 monoclonal antibody and mesenchymal stem cells in alginate microspheres for bone tissue engineering," Biomaterials, vol. 34, no. 28, pp. 6572-6579, 2013.

[53] S. Ansari, A. Moshaverinia, S. H. Pi, A. Han, A. I. Abdelhamid, and H. H. Zadeh, "Functionalization of scaffolds with chimeric anti-BMP-2 monoclonal antibodies for osseous regeneration," Biomaterials, vol. 34, no. 38, pp. 10191-10198, 2013.

[54] S. Ansari, M. O. Freire, E.-K. Pang, A. I. Abdelhamid, M. Almohaimeed, and H. H. Zadeh, "Immobilization of murine anti-BMP-2 monoclonal antibody on various biomaterials for bone tissue engineering," BioMed Research International, vol. 2014, Article ID 940860, 10 pages, 2014.

[55] S. Ansari, J. H. Phark, S. Duarte Jr. et al., "Biomechanical analysis of engineered bone with anti-BMP2 antibody immobilized on different scaffolds," Journal of Biomedical Materials 
Research. Part B, Applied Biomaterials, vol. 104, no. 7, pp. 1465-1473, 2016.

[56] Y. Xie, Y. Su, S. Min et al., "Collagen sponge functionalized with chimeric anti-BMP-2 monoclonal antibody mediates repair of critical-size mandibular continuity defects in a nonhuman primate model," BioMed Research International, vol. 2017, Article ID 8094152, 11 pages, 2017.

[57] L. Guo, S. Min, Y. Su et al., "Collagen sponge functionalized with chimeric anti-BMP-2 monoclonal antibody mediates repair of nonunion tibia defects in a nonhuman primate model: an exploratory study," Journal of Biomaterials Applications, vol. 32, no. 4, pp. 425-432, 2017.

[58] D. W. Dempster, J. E. Compston, M. K. Drezner et al., "Standardized nomenclature, symbols, and units for bone histomorphometry: a 2012 update of the report of the ASBMR Histomorphometry Nomenclature Committee," Journal of Bone and Mineral Research, vol. 28, no. 1, pp. 2-17, 2013.

[59] M. L. Nevins and M. A. Reynolds, "Tissue engineering with recombinant human platelet-derived growth factor BB for implant site development," The Compendium of Continuing Education in Dentistry, vol. 32, pp. 20-27, 2011.

[60] A. B. Castro, N. Meschi, A. Temmerman et al., "Regenerative potential of leucocyte- and platelet-rich fibrin. Part B: sinus floor elevation, alveolar ridge preservation and implant therapy. A systematic review," Journal of Clinical Periodontology, vol. 44, no. 2, pp. 225-234, 2017.

[61] E. A. Alkan, A. Parlar, B. Yildirim, and B. Sengüven, "Histological comparison of healing following tooth extraction with ridge preservation using enamel matrix derivatives versus Bio-Oss Collagen: a pilot study," International Journal of Oral and Maxillofacial Surgery, vol. 42, no. 12, pp. 1522-1528, 2013.

[62] A. M. Coomes, B. L. Mealey, G. Huynh-Ba, C. BarbozaArguello, W. S. Moore, and D. L. Cochran, "Buccal bone formation after flapless extraction: a randomized, controlled clinical trial comparing recombinant human bone morphogenetic protein 2/absorbable collagen carrier and collagen sponge alone," Journal of Periodontology, vol. 85, no. 4, pp. 525-535, 2014.

[63] R. Alissa, M. Esposito, K. Horner, and R. Oliver, "The influence of platelet-rich plasma on the healing of extraction sockets: an explorative randomised clinical trial," European Journal of Oral Implantology, vol. 3, no. 2, pp. 121-134, 2010.

[64] E. Anitua, A. Murias-Freijo, M. H. Alkhraisat, and G. Orive, "Clinical, radiographical, and histological outcomes of plasma rich in growth factors in extraction socket: a randomized controlled clinical trial," Clinical Oral Investigations, vol. 19, no. 3, pp. 589-600, 2015.

[65] M. Mozzati, G. Gallesio, S. di Romana, L. Bergamasco, and R. Pol, "Efficacy of plasma-rich growth factor in the healing of postextraction sockets in patients affected by insulindependent diabetes mellitus," Journal of Oral and Maxillofacial Surgery, vol. 72, no. 3, pp. 456-462, 2014.

[66] G. Chen, C. Deng, and Y. P. Li, “TGF- $\beta$ and BMP signaling in osteoblast differentiation and bone formation," International Journal of Biological Sciences, vol. 8, no. 2, pp. 272-288, 2012.

[67] W. K. Hsu and J. C. Wang, "The use of bone morphogenetic protein in spine fusion," The Spine Journal, vol. 8, no. 3, pp. 419-425, 2008.
[68] A. L. Jones, R. W. Bucholz, M. J. Bosse et al., "Recombinant human BMP-2 and allograft compared with autogenous bone graft for reconstruction of diaphyseal tibial fractures with cortical DEFECTS," The Journal of Bone and Joint Surgery. American Volume, vol. 88, no. 7, pp. 1431-1441, 2006.

[69] K. S. Cahill, J. H. Chi, A. Day, and E. B. Claus, "Prevalence, complications, and hospital charges associated with use of bone-morphogenetic proteins in spinal fusion procedures," JAMA, vol. 302, no. 1, pp. 58-66, 2009.

[70] G. M. Calori, D. Donati, C. Di Bella, and L. Tagliabue, "Bone morphogenetic proteins and tissue engineering: future directions," Injury, vol. 40, pp. S67-S76, 2009. 